\title{
Diagnostic and Monitoring System for Technical Condition of Electromechanical Section of Thermal Control Systems in Spacecraft
}

\author{
Stanislav A. Matveev \\ Vice-Rector for Scientific Work and Innovative Communication Technologies, \\ Faculty of Information and Control Systems, \\ Department of Control Systems and Computer Technology, \\ Baltic State Technical University «VOENMEH», \\ St. Petersburg, 190005, Russia. \\ Corresponding author: stas_matveev@mail.ru

\section{Evgeny B. Korotkov} \\ Faculty of Information and Control Systems, Department of Drive Systems, \\ Mechatronics and Robotics, Baltic State Technical University «VOENMEH», \\ St. Petersburg, 190005, Russia. \\ E-mail: ebkorotkov@yandex.ru

\section{Yuri A. Zhukov} \\ Faculty of Information and Control Systems, Department of Drive Systems, \\ Mechatronics and Robotics, Baltic State Technical University «VOENMEH», \\ St. Petersburg, 190005, Russia. \\ E-mail: zh_kv@mail.ru
}

\section{Nikita S. Slobodzian}

Faculty of Information and Control Systems, Department of Drive Systems, Mechatronics and Robotics, Baltic State Technical University «VOENMEH»,

St. Petersburg, 190005, Russia.

E-mail: ja-nikita@mail.ru

\section{Mikhail I. Nadezhin}

Faculty of Information and Control Systems,

Department of Drive Systems, Mechatronics and Robotics,

Baltic State Technical University «VOENMEH»,

St. Petersburg, 190005, Russia.

E-mail: skymale53@gmail.com

Andrei V. Gorbunov

Faculty of Information and Control Systems, Department of Control Systems and Computer Technology,

Baltic State Technical University «VOENMEH»,

St. Petersburg, 190005, Russia.

E-mail: anygos@yandex.ru

\section{Leonid T. Tanklevskiy}

Higher School of Technosphere Security,

Peter the Great St.Petersburg Polytechnic University,

St. Petersburg, 195220, Russia.

E-mail: tanklevskij_lt@ spbstu.ru

(Received April 15, 2019: Accepted September 18, 2019) 
International Journal of Mathematical, Engineering and Management Sciences

Vol. 5, No. 1, 181-192, 2020

https://doi.org/10.33889/IJMEMS.2020.5.1.015

\begin{abstract}
Modern diagnostics methods ensuring the safety of production and operation, as well as the improvement of functional characteristics of electromechanical systems' are discussed, method of diagnostics according to the spectrum and hodograph of the engine's equivalent current is presented. Functional concept is presented for the system of control, diagnostic and monitoring of technical condition of thermal control systems' electromechanical part in the spacecraft. The decision-making and forecasting algorithm for the operational resource is based on ground-based studies and diagnostic results. This approach to device diagnostics and monitoring is also used in other servo drives, mechatronic and robotic systems of space vehicles and other objects that are inaccessible and left unattended. Hardware-algorithmic implementation of the system is described, recommendations on the components base selection are given.
\end{abstract}

Keywords- Diagnostics, Monitoring, Thermal control system, Electrically driven pump, Electric motor.

\title{
1. Introduction
}

At designing modern spacecraft (SC) and on-board systems the developers are primarily striving for ensuring the safety of their production and operation and improving weight-size parameters and power and functional characteristics at general growth of reliability and operational lifetime extension.

The principal factors influencing stability characteristics and reliability of the on-board equipment and SC on the whole are the outer space's ionizing radiation and electromagnetic, thermal and mechanical effect of the SC's systems on each other (Maksimov, 2010), as well as the processes of heat absorption and dissipation by the SC's and its elements' surface heat exchange with the environment by radiation.

In the SC, maintaining the required operating temperatures of the on-board equipment during the entire life-time is ensured by the thermal environment support system that is thermal control system (TCS). Modern SC's liquid thermal control systems with cooling efficiency of 5-15 kW are active (Testoedov et al., 2016), and circulation of heat transfer agent based on isooctane takes place in them along the TCS's hydraulic system with the help of the supercharger, that is electric driven pump (EDP). Also, active TCS contains radiators, piping, temperature regulators and valves operating according to the signals of the on-board digital computer (Cai, 2001).

A standard TCS's electric driven pump is completed with two similar electrically driven centrifugal hydraulic pumps (the major pump and the stand-by one). When failure of the EDP's major channel is identified in the process of TCS operation switching to the stand-by channel is undertaken. Analysis of the SC operating experience shows (Testoedov et al., 2015) that active TCS's reliable operation is primarily determined by reliability of EDP and its principal elements, namely: electric motor and its control system, bearing assemblies (Shtukin et al., 2016; Indeitsev et al., 2018).

In the life-time of SC and its components, EDP motors in particular, testing and functional diagnostic stages are implemented. During the former stage performed within the range of the pre-flight ground testing, practically all possible types of electrical and mechanical damages are identified (Xue et al., 2016). However, diagnostics and continuous monitoring of EDP parameters sufficient for the incipient failure detection and prognosis of the units's condition are not carried out for the SC's thermal control systems during the operating stage (Patraev, 2010).

As EDP drive motors, permanent magnet synchronous motors (PMSM) are used having such advantages as absence of nonreliable collector-and-brush assembly unit, ability of direct control with 
International Journal of Mathematical, Engineering and Management Sciences

Vol. 5, No. 1, 181-192, 2020

https://doi.org/10.33889/IJMEMS.2020.5.1.015

ungeared connection of load, and high-rate specific power. As a disadvantage, need for the specialpurpose electronic control device substituting collector-and-brush assembly unit and regulating phase currents in compliance with the rotor's given position (i.e., ensuring operating condition of the brushless direct current motor BLDC) should be mentioned (Stolyarov and Ershov, 2017; Porubov et al., 2018).

According to the statistics (Geitner and Bloch, 2012), failure of the pumping units is caused by the following reasons (in the order of maximum effect): seals destruction; bearings failure; rotary driven gear defects and feeding fixture; drive housing rupture. The principal widespread defects of the synchronous motors's electrical and mechanical systems are as follows (Muenchhof et al., 2009): bearings failure; overheat, breakage, or interturn short circuit of stator's phase windings; short circuit between phases; change in the stator-to-rotor gap; rotor imbalance; torque overload; overheat of rotor's permanent magnets; power electronics's faults. The above-mentioned defects can result in both parametric and functional failure of TCS, and in general case decrease the SC's life-time operation (Ziniakov et al., 2016; Parsunkin et al., 2017).

Thus, to improve the SC reliability, the topical issue of TCS's EDP diagnostics based on the continuous monitoring of the electromechanical section's parameters should be solved ensuring identification of the residual operating life, as well as functional and parametric failure (Budanov et al., 2017; Davydov et al., 2017; Repin and Valdman, 2018). The current work objective is review of the diagnostic methods of drives based on synchronous motors with permanent magnets, as well as substantiation of the monitoring parameters's choice and formation of functional scheme of the EDP's diagnostic system.

\section{Methods of Diagnostics}

Currently, diagnostics of pumping unit's electro drives is carried out by multiple methods developed based on handling readings of the instrument converters such as acoustic and vibration probes, current and voltage sensors, temperature gages, and electromagnetic transformers. In the diagnostic systems, preliminary processing of the instruments' initial information is performed followed by recognition and classification of the drive's defects on the real-time basis.

Since SC' EDP consists of the electrical and mechanical subsystems, a two-direction comprehensive diagnostics of faults is required: identification of mechanical and electromagnetic defects of the unit.

Great majority of the modern methods applied for diagnostics of machines' and mechanisms' mechanical system is based on the analysis of vibration signals from the primary detectors initial sensor; spectral (fast Fourier transformation) (Petukhov et al., 2007), frequency and wavelet images of signals (Adams, 2000). Bispectral methods of processing presented in (Benbouzid, 2000; Halim et al., 2007) showed good results. In (Attoui et al., 2017) an example of applying wavelet packet transformation (WPT) for bearing defects diagnostics is given.

Diagnostics of EDP electric motor faults is based on measurement of the electric motor's current, voltage, electromagnetic flow, temperature, torque and vibration. Methods of vibrodiagnostics are rather well developed and are currently used in the electric drive systems (Kalinov and Bratash, 2012). For the purpose of diagnostics of faults in synchronous motors with permanent magnets in operation (Alameh et al., 2015), substantiation of the modern vibrational diagnostics methods is given. In practice (Bulgakova and Kruglova, 2017; Silva et al., 2018), spectral and wavelet methods of information's processing are successfully applied. 
International Journal of Mathematical, Engineering and Management Sciences

Vol. 5, No. 1, 181-192, 2020

https://doi.org/10.33889/IJMEMS.2020.5.1.015

Such defects as damage, interruption, interturn and interphase short circuit of the stator windings are diagnosed according to the instantaneous levels of phase currents and voltages (Urrestya et al., 2012). For instance, phase current's zero value in the presence of the generated phase voltage is indicative of the corresponding phase break (interruption). While analyzing the total current consumption and voltage of the control device supply faults of the input circuits of supply and its internal blocks are diagnosed. In the article (Picot et al., 2014), advantages of the current signals' statistical analysis based on discrete valuation of the signal power's spectral density - Welch periodogram - are demonstrated. In work of Moosavi et al. (2015), review of methods used for PMSM rotor demagnetization's evaluation is presented. Moreover, measuring of local temperature in critical points of the structure is performed to ensure full-scale diagnostics (Waqar and Demetgul, 2016).

Of special complexity is the task of the faults' recognition and classification based on the signs identified in the primary signals. Machine learning methods are the most popular ones (Sobie et al., 2018) including: statistical methods based on regression analysis, random trees, reference vectors; neural network methods based on feed-forward networks, recurrent and convoluted networks; neurofuzzy methods based on the fuzzy logic rules. Thus, in the article (Quiroz et al., 2018), algorithms of rotor faults classification based on the random forest are proposed. In the work (Yan and Jia, 2018), the optimized Support Vector Method is proposed for bearing faults classification based on the pooled analysis of signals in time, frequency and VMD (Variational Mode Decomposition) domains. In the work (Nyanteh et al., 2013), neural network assembly application is proposed for processing of phase currencies and for classification of the synchronous machine faults based on the particle swarm optimization (PSO) method.

The above-listed diagnostic methods feature plenty of advantages. However, not all of them suite for the diagnostic systems' implementation on a real-time basis since they require computation of complex conversions in real time. So, the proposed methods implementation is accompanied by the need for defining primary parameters adequate for diagnostics, as well as diagnostic methods and hardware base.

In this article we propose to define the motor condition according to the equivalent current Iq in addition to the above-mentioned methods. The PMSM type machines control strategy involves generating of the stator's rotating magnetic field by supplying its phases with the alternating voltages displaced relative to each other by 120 degrees (for three-phase machine). A drive is produced at closing of the said motor by feedback communication according to the rotor position and by maintaining orientation of the stator's magnetic field vector at 90 degrees angle. The said drive features are similar to those of the DC motor where the armature current is proportional to the torque on the shaft, while the voltage is proportional to the shaft speed.

At that, for the PMSM analysis, equivalent current Iq is calculated according to the signals of sensors of the PMSM stator's three-phase currents and voltages with the help of Clarkes' and Parks' transformations (Krause et al., 2013). Based on the said calculation, torque perturbations and their frequency constituents (and, possibly, the said perturbation's sources) are defined.

As an example, spectral characteristic of the equivalent current Iq is demonstrated in Figure 1. Since the real signal always contains multiple frequency constituents, weak constituents with the level compatible with the noise level are cut-off prior to the analysis. So, only constituents having characteristic frequencies above the certain threshold value are shown on the spectrum. The said 
International Journal of Mathematical, Engineering and Management Sciences

Vol. 5, No. 1, 181-192, 2020

https://doi.org/10.33889/IJMEMS.2020.5.1.015

threshold value is selected experimentally, and makes $0.02 \mathrm{~A}$ for the discussed motor. Also, it should be mentioned that in the real spectrum signal multiple spikes can be observed on the neighbouring frequencies (Hertz fractions) being manifested as a result of minor changes in frequencies of the discussed signals' harmonic constituents. Essentially, the sum of amplitudes of the said spikes reflects amplitude value on the certain average frequency. That is why the said effect is eliminated by summing of the said constituents prior to the analysis.

Currency level on the zero frequency reflects the constant torque component, and it is not shown in the diagram for the purpose of visual clarity of other values. The first spike on frequency of $400 \mathrm{~Hz}$ is related to the torque pole pulsation (the motor rotates at $100 \mathrm{~Hz}$ frequency, and has four pairs of poles). The spike existing on frequency of $1.2 \mathrm{kHz}$ reflects distinctive features of the EDP motor load - the pump's centrifugal impeller having 12 blades. The strike on frequency of $2.4 \mathrm{kHz}$ is related to the current pole pulsations (the motor is commutated by trapezoidal waveform and has 12 pairs of poles). The strike on frequency of about $15.5 \mathrm{kHz}$ is related to the fact that alternating phase voltages are generated with the help of pulse-width modulation with the corresponding frequency.

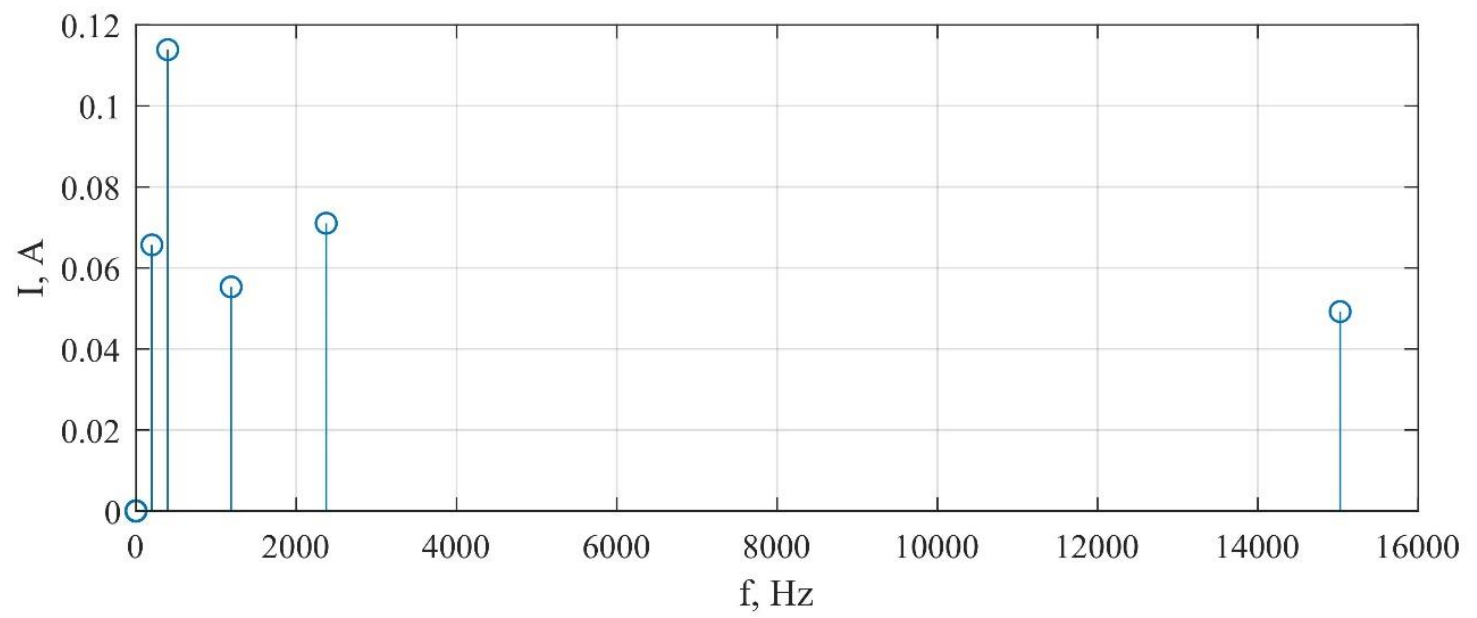

Figure 1. Spectral characteristic of the equivalent current Iq

The major faults of the electric motor are identified on the following characteristic frequencies (Thomson and Fenger, 2001): damages of the stator windings and rotor damages - on the supply mains frequency; the motor shafts misalignment and mechanical devices related to the electric motor, the load imbalance - on the rotor spinning frequency and on frequencies multiple of it; damages of bearings - on frequencies multiple of the rotor spinning frequency; damages of the pump impeller (EDP) - on the blade frequency. Thus, to diagnosed the electric motor operation it is necessary to analyse changes in the signal level on the characteristic frequencies.

To diagnose the drive's electromechanical system based on the spatial pattern of the stator's electromagnetic field distribution, method of analysis of the equivalent current vector's hodograph in coordinates I $\alpha$ and I $\beta$ produced by Clarke's transformation (Ciprian and Loránd, 2011). Figure 2 shows simulation model of the EDP's electromechanical system and electronic commutator developed in MATLAB Simulink and intended for study of the equivalent current vector's hodograph. 


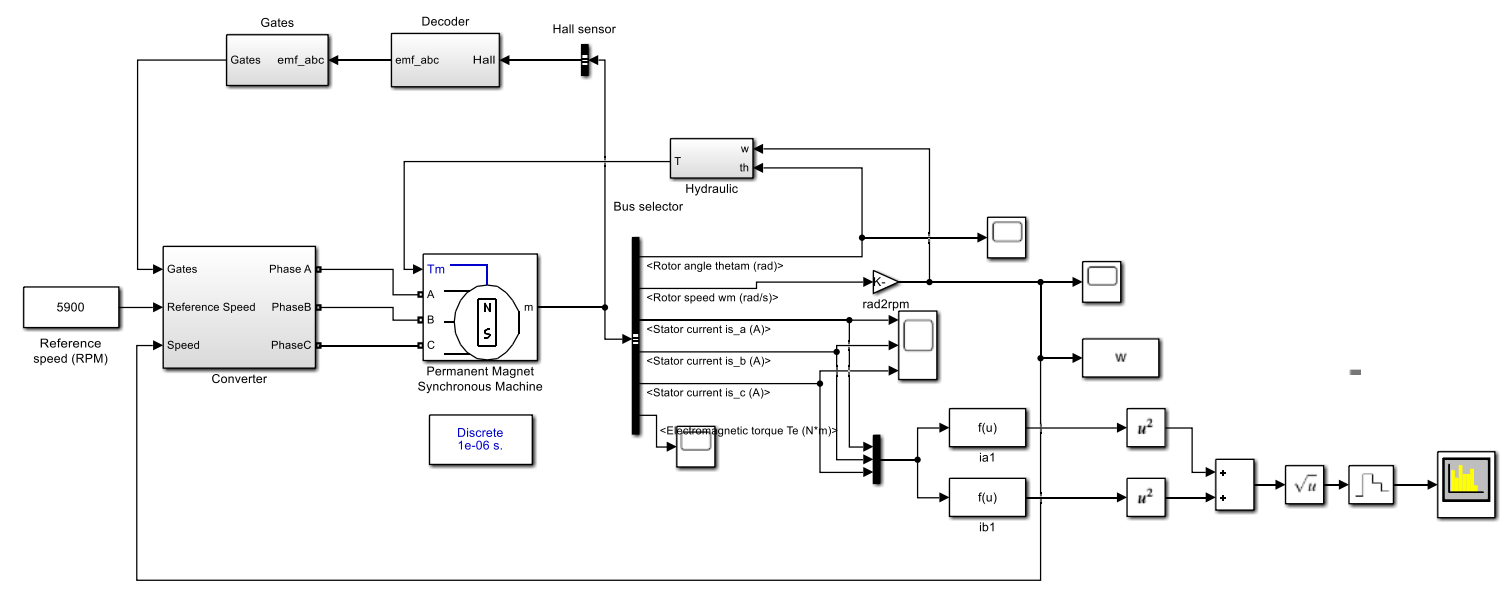

Figure 2. Simulation model of electromechanical system and electronic commutator

In the model, EDP motor control is performed as follows: at the electric power supply voltage, the entry code on the rotor position sensor buses (Hall Sensor block) is decoded (Decoder block) into the signals of control of the power transistor bridge switches (Gates block). With the help of the transistor switches keys connection to the power supply source of the corresponding winding of each of three phases of the motor. The power transistor bridge together with the rest of elements of the converter are realized in the Converter block. The EDP motor load is preset by the Hydraulic block. The rest of blocks are standard MATLAB Simulink blocks.

Figure 3 shows the equivalent current vector's hodograph plotted using the simulation model at rectangular pulses of PMSM-type motor control. If currents in phases have trapezoid shape the equivalent current vector's hodograph is of a star shape.

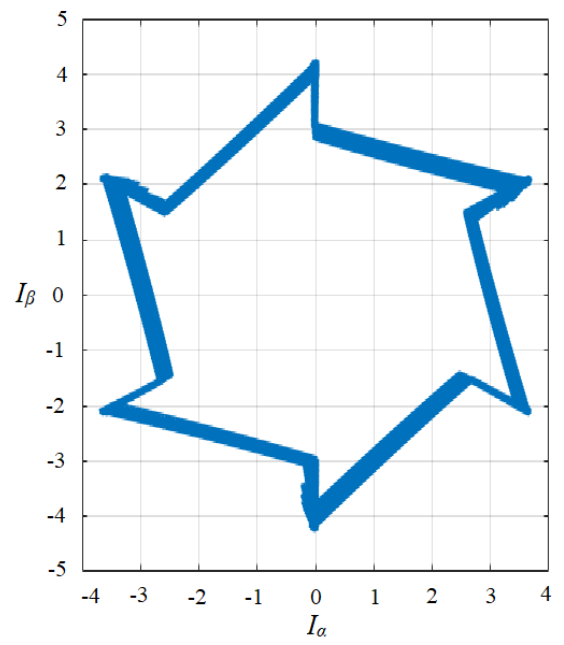

Figure 3. The equivalent current vector hodograph of the EDP motor's simulation model 
International Journal of Mathematical, Engineering and Management Sciences

Vol. 5, No. 1, 181-192, 2020

https://doi.org/10.33889/IJMEMS.2020.5.1.015

In Figure 4, the actual motor's equivalent current vector hodograph in the rated operating conditions as a part of EDP is demonstrated. Difference the shape of hodographs of the modeled and the actual motors relates to the availability of load on the motor shaft, as well as to the non-ideal nature of the control signals and the stator's structure.

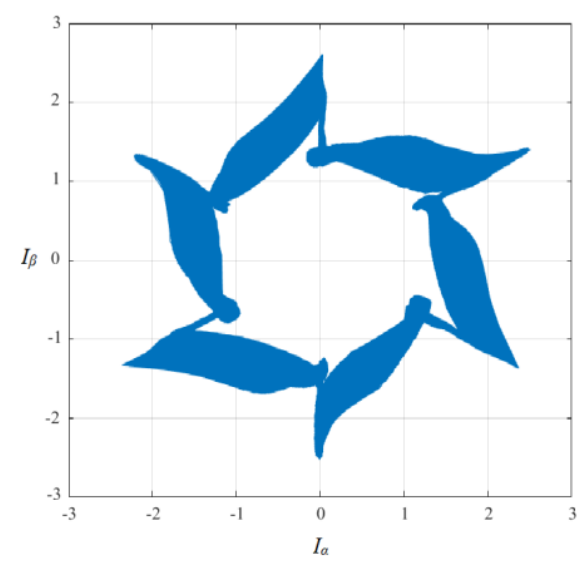

Figure 4. The equivalent current vector hodograph of the PMSM

Figure 5 shows the actual motor's equivalent current vector hodograph with the defect of the rotor position sensor at testing in in the rated operating conditions as a part of EDP. The sensor defect is the reason of irregular commutation of the PMSM phases, which influences the hodograph shape.

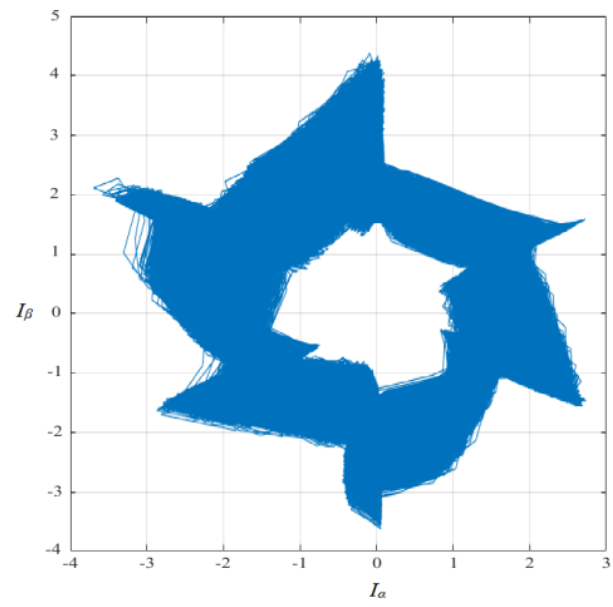

Figure 5. The equivalent current vector hodograph of the failed motor

Thus, EDP motor condition is diagnosed by way of performing comprehensive analysis of the electrical and mechanical parameters. Taking into account a vast amount of the analyzed data and absence of possibility to achieve a clear-cut mathematical description of the dependencies, it would be reasonable to use neural network method of diagnostics. Artificial neural network is implemented, 
International Journal of Mathematical, Engineering and Management Sciences

Vol. 5, No. 1, 181-192, 2020

https://doi.org/10.33889/IJMEMS.2020.5.1.015

for instance, on the microcontroller base, and is trained according to the signals of the primary parameters sensors in the presence of the artificially developed and admittedly known faults in the course of ground-based investigations of the electric motor and the entire electromechanical system.

\section{General Strategy of the System Design}

Modern methods of the PMSM's vector control imply availability of a high-performance microcontroller as part of the control system. Since diagnostic of operation requires sensor signals's picking-up, transformation and analysis, it would be reasonable to impose functions of the monitoring and diagnostic systems on the PMSM's control system either.

In Figure 6, functional diagram of the said system for one channel of the EDP (for one electric motor).

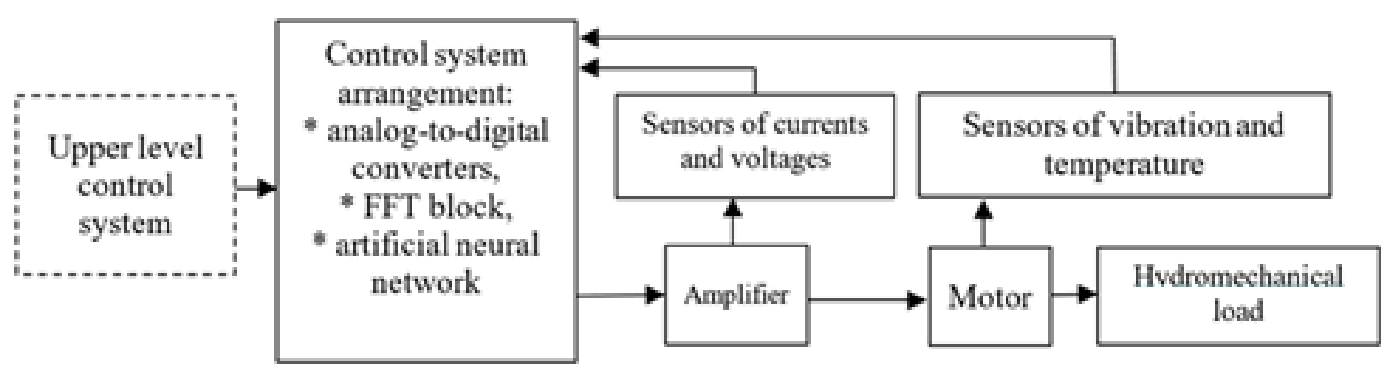

Figure 6. Functional diagram of the EDP electric motor control, monitoring and diagnostic system

The system includes a control device, amplifier, electric motor with the connected hydromechanical load (the pump's impeller and the EDP's hydraulic system), block of sensors of the electric motor winding's currents and voltages and the common current and voltage of the amplifier's power supply, vibration and temperature sensors of the electric motor housing and bearings.

Outputs of the primary value sensors are connected to the control device that is completed not only with the amplifier control signals conditioner but also with the analog-digital converters, fastFourier-transform block, as well as with the artificial neural network performing diagnostics of the system's technical condition.

The system operates as follows. In normal operating mode, based on the signals of the shaft angular position sensor, the control device generates signals of the amplifier control that, in turn, supplies the enhanced signals onto the electric motor windings.

In the course of the system operation, continuous diagnostics of the electric motor technical condition takes place. Signals of sensors of current, voltage, vibratory acceleration and temperature of the electric motor housing and bearings enter the control device where their analog-digital conversion and filtration take place, fast Fourier transformation is performed and information on the said parameter's spectral constituent is generated. Further, the processed signals enter the specially trained neural network. At the said neural network's output the code is formed identifying one of the electric motor's electromechanical failure (or the failure family) with the corresponding weight coefficients. 
International Journal of Mathematical, Engineering and Management Sciences

Vol. 5, No. 1, 181-192, 2020

https://doi.org/10.33889/IJMEMS.2020.5.1.015

At that, weight coefficients reflect the residual operation time and presence of functional or parametric fault. Thus, it is possible to define the level and nature of the rolling bearings' wear based on the spectral characteristic of the primary signals of the vibratory acceleration sensors. At that, the motor's shaft speed is decreased down to the minimum permissible in order to improve the EDP's operational time duration. In case of the functional failure identification the control device turns-off the electric motor and delivers the corresponding information to the upper level control system so that the EDP's stand-by channel be turned-on.

Considering the requirements for reliability and resistibility to the external influencing factors it would be reasonable to use the following instrumentation as the primary sensors of the monitored parameters: current shunts; resistive (resistance) voltage dividers; piezoelectric sensors of vibratory accelerations; resistance temperature sensors.

The above-described program-algorithmic functional (complex) can be implemented on the modern microprocessor device, for instance, on the radiation-resistant 32-bit 1986BE8 Series Microcontroller (MC) manufactured by AO PKK Milandr (Russia). The said MC is developed on the basis of Cortex-M4F process core and is completed with the timer hardware modules. PWM signals that are delivered on the amplifier unit and further onto the motor's windings can be formed on the said timer hardware modules (Zhukov et al., 2017).

Measurement of currents, voltages, temperatures and values of vibratory accelerations is carried out using MC's analog-digital conversion block. Cortex-M4F process core maintains instructions on digital signal processing (DSP) at the software-hardware level, which allows implementing computation of the spectral characteristics in real time, for instance, with the help of fast Fourier transformation. At that, it is basically possible to follow the extended telemetering information on virtually a real time basis since calculation of all the required characteristics is executed by the monitoring and diagnostic system means, which, in addition, allows ground control centres performing analysis of the current operating conditions of TCS and SC on the whole and promptly make adequate decision.

On a separate note, it is possible to ensure maintaining stable temperature of the SC's on-board equipment in more narrow range, irrespective of the environmental conditions and the equipment operating conditions, by adjusting the heat-transfer agent consumption. Such methods of consumption adjustment as application of bypass adjustment scheme or use of EDP blades made of the shape memory alloy (Krushenko and Golovanova, 2014) have the advantage of the design simplicity. At the same time, they feature such evident drawbacks as relatively complicated technology of TCS elements fabrication, limited range of adjustment, as well as change of own hydraulic characteristics in the course of adjustment. However, in the closed-loop systems of electric drive on the base of PMSM, smooth adjustment of the impeller rotation speed (and, consequently, the heat-transfer agent consumption) is quite simply implemented and does not require any special equipment, which allows improving overall efficiency of the SC's temperature control system.

\section{Conclusions}

The discussed methods allow diagnosing technical condition of electromechanical system of spacecraft's temperature control systems. Current diagnostic method is the advanced one.

The described system makes it possible not only to control the EDP motor, but also ensures monitoring and diagnostics of the TCS's electromechanical system. The system includes the primary 
International Journal of Mathematical, Engineering and Management Sciences

Vol. 5, No. 1, 181-192, 2020

https://doi.org/10.33889/IJMEMS.2020.5.1.015

sensors, devices for the primary sensors signals processing, and control device, and analyses electrical, mechanical (vibrational) and temperature parameters of the EDP. Algorithm of the monitoring and diagnostic system operation envisages getting the information from the primary diagnostic sensors, processing of their signals, comparison of the signals, decision-making, operational life forecast and diagnostic information output. Algorithm of the decision-making and operational life forecast is based on the ground investigations and diagnostic results. The said approach to arrangement of the diagnostic and monitoring system can be also used in other servo drivers, mechatronic and robotic systems of spacecraft and other objects of awkward-to-reach and unattended equipment. At that, it would be reasonable to correct operating conditions of the EDP motors in order to improve their operating life, which is particularly topical for the modern spacecraft with long periods of active operation, i.e. up to 15 years.

Further studies objective is defining of the optimum set of primary monitored parameters and more efficient diagnostic methods by way of their comparative analysis while the EDP electric motor's control, monitoring and diagnostic system is operating as part of the TCS.

\section{Conflict of Interest}

The authors confirm that there is no conflict of interest to declare for this publication

\section{Acknowledgments}

The work is carried out with the financial support of the Ministry of Education and Science of the Russian Federation (agreement No. 14.577.21.0270, unique project number RFMEFI57717X0270).

\section{References}

Adams, M.L. (2000). Rotating machinery vibration from analysis to troubleshooting. CRP Press, New York: Marcel Dekker.

Alameh, K., Cité, N., Hoblos, G., \& Barakat, G. (2015). Vibration-based fault diagnosis approach for permanent magnet synchronous motors. IFAC-PapersOnLine, 48(21), 1444-1450.

Attoui, I., Fergani, N., Boutasseta, N., Oudjani, B., \& Deliou, A. (2017). A new time-frequency method for identification and classification of ball bearing faults. Journal of Sound and Vibration, 397, 241-265.

Benbouzid, M.E. (October 2000). A review of induction motors signature analysis as a medium for faults detection. IEEE Transactions on Industrial Electronics, 47(5), 984-993.

Budanov, D.O., Morozov, D.V., \& Pilipko, M.M. (2017). An 8-bit flash analog-to-digital converter with an array of redundant comparators. Journal of Communications Technology and Electronics, 62(4), 421431. doi:10.1134/S1064226917040027.

Bulgakov, A., \& Kruglova, T. (2017). Intelligent method for fault finding of electric drive based on wavelet analysis of its electrical and mechanical parameters. Procedia Engineering, 206, 929-935.

Cai, K. C. (2001). On the neural network approach in software reliability modeling. Journal of Systems and Software, 4-62.

Ciprian, H., \& Loránd, S. (2011). Wavelet analysis and park's vector based condition monitoring of induction machines. Juornal of Computer Science and Control Systems, 4(2), 35-38. 
International Journal of Mathematical, Engineering and Management Sciences

Vol. 5, No. 1, 181-192, 2020

https://doi.org/10.33889/IJMEMS.2020.5.1.015

Davydov, V.V., Myazin, N.S., \& Davydova, T.I. (2017). A nondestructive method for express testing of condensed media in ecological monitoring. Russian Journal of Nondestructive Testing, 53(7), 520-529. doi:10.1134/S106183091707004X.

Geitner, F.K., \& Bloch, H.P. (2012). Machinery failure analysis and troubleshooting (Fourth Edition). Butterworth Heinemann.

Halim, E.B., Choudhury, M.S., Shah, S.L., \& Zuo, M.J. (2006). Fault detection of rotating machinery from bicoherence analysis of vibration data. IFAC Proceedings Volumes, 39(13), 1348-1353.

Indeitsev, D.A., Loboda, O.S., Morozov, N.F., Skubov, D.Y., \& Shtukin, L.V. (2018). Self-oscillating mode of a nanoresonator. Physical Mesomechanics, 21(3), 203-207. doi:10.1134/S1029959918030037.

Kalinov, A.P., \& Bratash, O.V. (2012). Analysis of the methods of vibrodiagnostics of asynchronous motors. EHnergetika. Izvestiya vysshikh uchebnykh zavedenij i ehnergeticheskikh ob"edinenij SNG, 5, 43-51 [In Russian]

Krause, P., Wasynczuk, O., Sudhoff, S., \& Pekarek, S. (2013). Analysis of electric machinery and drive systems. NJ: Wiley-IEEE Press. doi:10.1002/9781118524336.

Krushenko, G.G., \& Golovanova, V.V. (2014). Improving the thermal control system of spacecraft. In Sibirskij zhurnal nauki i tekhnologij, 3(55), 185-189 [In Russian].

Maksimov, I.A. (2010). Problems of ensuring the reliable functioning of modern spacecraft under the destabilizing effects of space factors and man-made factors. Sibirskij zhurnal nauki i tekhnologij, 4(30), 100-101. [In Russian].

Moosavi, S.S., Djerdir, A., Amirat, Y.Ait., \& Khaburi, D.A. (2015). Demagnetization fault diagnosis in permanent magnet synchronous motors:A review of the state-of-the-art. Journal of Magnetism and Magnetic Materials, 391, 203-212.

Muenchhof, M., Beck, M., \& Isermann, R. (2009). Fault-tolerant actuators and drives-Structures, fault detection principles and applications. Annual Reviews in Control, 33(2), 136-148.

Nyanteh, Y.D., Srivastava, S.K., Edrington, C.S., \& Cartes, D.A. (2013). Application of artificial intelligence to stator winding fault diagnosis in Permanent Magnet Synchronous Machines. Electric Power Systems Research, 103, 201-213.

Parsunkin, B.N., Lednov, A.V., Sukhonosova, T.G., \& Lednova, J. (2017). Testing signals formation for identification of heat power objects and control systems comparison. The International Journal of Advanced Manufacturing Technology, 93(9-12), 3429-3436. doi:10.1007/s00170-017-0788-x.

Patraev, V.E. (2010). Methods to ensure and assess the reliability of spacecraft with a long active life. Sib. gos. aehrokosmich. un-t, Krasnoyarsk. [In Russian].

Petukhov, V.S., Sokolov, V.A., Grigor'ev, O.A., Velikij, S.N., \& Mikhel', A.A. (2007). Mode of diagnostics od electrical engines of alternating current and of mechanical arrangements involved with them. Russia Patent № 2300116.

Picot, A., Obeid, Z., Régnier, J., Poignant, S., Darnis, O., \& Maussion, P. (2014). Statistic-based spectral indicator for bearing fault detection in permanent-magnet synchronous machines using the stator current. Mechanical Systems and Signal Processing, 46(2), 424-441.

Porubov, A.V., Osokina, A.E., \& Michelitch, T.M. (2018). Operator approach to square lattice nonlinear dynamics. Materials Physics and Mechanics, 35, 139-144. doi:10.18720/MPM.3512018_16.

Quiroz, J.C., Mariun, N., Mehrjou, M.R., Izadid, M., Misron, N., \& Radzi, M.A.M. (2018). Fault detection of broken rotor bar in LS-PMSM using random forests. Measurement, 116, 273-280.

Repin, S., \& Valdman, J. (2018). Error identities for variational problems with obstacles. ZAMM Zeitschrift Fur Angewandte Mathematik Und Mechanik, 98(4), 635-658. doi:10.1002/zamm.201700105. 
International Journal of Mathematical, Engineering and Management Sciences

Vol. 5, No. 1, 181-192, 2020

https://doi.org/10.33889/IJMEMS.2020.5.1.015

Shtukin, L.V., Berinskii, I.E., Indeitsev, D.A., Morozov, N.F., \& Skubov, D. Yu. (2016). Electromechanical models of nanoresonators. Physical Mesomechanics, 19(3), 248-254. doi:10.1134/S1029959916030036.

Silva, A.A., Gupta, S., Bazzi, A.M., \& Ulatowski, A. (2018). Wavelet-based information filtering for fault diagnosis of electric drive systems in electric ships. ISA Transactions, 78, 105-115.

Sobie, C., Freitas, C., \& Nicolai, M. (2018). Simulation-driven machine learning: bearing fault classification. Mechanical Systems and Signal Processing, 99, 403-419.

Stolyarov, O., \& Ershov, S. (2017). Characterization of change in polypropylene spunbond nonwoven fabric fiber orientation during deformation based on image analysis and fourier transforms. The Journal of Strain Analysis for Engineering Design, 52(8), 457-466.

Testoedov, N.A., Khalimanovich, V.I., Sin'kovskij, F.K., Kolesnikov, A.P., Legostaj, I.V., Golovenkin, E.N., Ankudinov, A.V., Oleg Valentinovich, Krivov, E.V., Akchurin, G.V., Butkina, N.F., Kudrjavtseva, N.V., \& Akchurin, V.P.(2016). Heat regulating system of space vehicle. Russia Patent № 2577925.

Testoedov, N.A., Dvirnyj, V.V., Morozov, E.A., Dvirnyj, G.V., \& Eremenko, N.V. (2015). Increased durability of spacecraft instruments. In Sibirskij Zhurnal Nauki i Tekhnologij, 16(2), 430-437. [In Russian].

Thomson, W.T., \& Fenger,.M. (2001). Current signature analysis to detect induction motor faults. IEEE Industry Application Magazine, 7(4), 26-34.

Urrestya, J.-C., Ribab, J.-R., \& Romerala, L. (2012). Application of the zero-sequence voltage component to detect stator winding inter-turn faults in PMSMs. Electric Power Systems Research, 89, 38- 44.

Waqar, T., \& Demetgul, M. (2016). Thermal analysis MLP neural network based fault diagnosis on worm gears. Measurement, 86, 56-66.

Xue, W., Shang, W., Makarov, S.B., \& Xu, Y. (2016). A phase trajectories optimization method for CPM signal based on pan-function model. Eurasip Journal on Advances in Signal Processing, 55(2016) doi:10.1186/s13634-016-0351-1.

Yan, X., \& Jia, M. (2018). A novel optimized SVM classification algorithm with multi-domain feature and its application to fault diagnosis of rolling bearing. Neurocomputing, 313, 47-64.

Zhukov, Y.A., Korotkov, E.B., \& Slobodzyan, N.S. (2017). Radiation resistant microcontroller with CortexM4F core based control system of parallel kinematics mechanism designed for spacecraft's onboard devices movements. Voprosy radioelektroniki, 7, 48-53.

Ziniakov, V.Y., Gorodetskiy, A.E., \& Tarasova, I.L. (2016). System failure probability modelling Studies in Systems, Decision and Control, 49, 205-215.doi:10.1007/978-3-319-27547-5_19. 